\title{
Erratum
}

\section{Review Article: The early modern foundations of the modern world: recent works on patterns of economic and political change - Erratum}

\author{
R. Bin Wong
}

The publishers regret to announce that an error was published in the above publication ${ }^{1}$. On page 136, the below sentence should have read "European colonies in the Americas":

"Usefully, Parker contextualizes the vast crisis-affected area in spatial terms by noting two kinds of exceptions to this pervasive pattern - unscathed places including European colonies in America, South and Southeast Asia, and Japan; and places where the impact of the little ice age was ambiguous, such as the Great Plains of North America, sub-Saharan Africa, and Australia.”

The publishers apologize for this error.

1 R. Bin Wong (2016). Review of Geoffrey Parker 'Global crisis: war, climate change and catastrophe in the seventeenth century’ Journal of Global History, 11, pp 135-146. doi:10.1017/S1740022815000388. 